\title{
Commuting Distance of Rural Migrants in Urban China: The Role of Educational Attainment
}

\author{
Mingjie Sheng ${ }^{*}$, Weiping $\mathrm{Wu}^{2}$, Chaolin $\mathrm{Gu}^{1}$ \\ ${ }^{1}$ School of Architecture, Tsinghua University, Beijing, China \\ ${ }^{2}$ Department of Urban and Environmental Policy and Planning, Tufts University, Medford, MA, USA \\ Email: *roseroseroseming@hotmail.com
}

Received 21 September 2015; accepted 25 October 2015; published 29 October 2015

Copyright (C) 2015 by authors and Scientific Research Publishing Inc.

This work is licensed under the Creative Commons Attribution International License (CC BY). http://creativecommons.org/licenses/by/4.0/

(c) (i) Open Access

\begin{abstract}
Commuting distance is directly affected by residential location choice. Most studies examining commuting distance are rooted in the context of a functioning housing market where housing choice is treated as an endogenous variable based on utility maximization. However, in China, institutional forces largely exclude rural migrants from urban mainstream housing systems, and make housing choice an exogenous variable. Therefore, examining migrant commuting distance will help understand how they react to housing market barriers when making workplace location decisions. Given the increasing role of educational attainment in migrant employment outcomes, this paper examines the relationship between migrant educational attainment and commuting distance. Drawing from survey data collected in the capital city Beijing, this paper highlights years of education serving as the strongest predictor of migrant commuting distance. In addition, this paper shows that migrants with a low level of educational attainment are more constrained to nearby informal sector employment, while their counterparts with higher educational attainment are more able to participate in the citywide labor market.
\end{abstract}

Keywords

Migrant, Commuting Distance, Educational Attainment, Institutional Barriers, China

\section{Introduction}

For decades, scholars have attempted to analyze commuting distance in the context of socio-spatial equity, for it

${ }^{*}$ Corresponding author. 
represents the spatial separation of residential locations and workplace locations among different social groups (Wyly, 1996; McLafferty \& Preston, 1997; Sultana, 2003; Blumenberg, 2004). Commuting distance is mostly decided as a result of utilities provided by workplace and home locations (Romani et al., 2003). Most of the empirical studies examining migrant commuting distance are conducted in the context of developed countries such as the United Kingdom (Findlay et al., 2001; Champion et al., 2009) and Canada (Axisa et al., 2012ab; Maoh \& Tang, 2012). These studies often give primacy to market forces in the housing sector and treat housing choice as an endogenous variable which is based on utility maximization (Dieleman, 2001). In this circumstance, migrants are expected to change residential location to attain a balance of wages, housing prices and commuting costs. Longer commutes are often compensated by lower housing costs or better neighborhood amenities (Martin, 2001).

However, in the context of urban China where institutional forces play an important role in the housing sector, rural migrants' housing choice is more like an exogenous variable. Municipal government places strict limits on the supply of affordable housing for migrants as well as their ability to obtain housing finance. Without urban household registration (hukou), rural migrants are largely excluded from the urban mainstream housing systems (Wu, 2002), especially in large cities. As a result, many migrants have no choice but to live in "urban villages" (Chengzhongcun) which are famous for their low rent and chaotic land use, and often are identified as informal settlements. Unfortunately, recent demolishment of urban villages led by city governments has forced migrants to relocate to further peripheral areas (Gu et al., 2015). Therefore, migrant housing choice in urban China is subject to institutional barriers, and thus migrants make residential moves largely because they are forced to, not based on maximizing net benefits. Given the exogenous nature of migrant housing choice in urban China, examining migrant commuting distance may shed light on how they react to housing market barriers when making workplace location decisions.

In the general literature on commuting distance, many scholars have examined the role of race (Taylor \& Ong, 1995; Gottlieb \& Lentnek, 2001; Sultana, 2003) or gender (Hanson \& Johnston, 1985; McLafferty \& Preston, 1997; Blumenberg, 2004). However, for rural migrants in China, educational attainment likely serves as a more important factor. Since China is undergoing rapid urbanization, millions of rural migrants have moved to large cities. The first wave of rural migrants who are featured by low educational attainment often hold low socio-economic status and thus are at a disadvantage. Therefore, recently there have been policies aimed at increasing rural individual access to higher education, such as the college enrollment expansion plan. As a result, rural-urban migrants have been educationally diversified in recent years. Several scholars have already noticed the increasing role of educational attainment in deciding migrant employment outcomes (Zhang et al., 2002; Brauw \& Rozelle, 2008; Lu \& Song, 2006) and access to social benefits (Wu \& Wang, 2014). However, the effect of educational attainment on migrant commuting distance, which can serve as a proxy for the job-housing spatial relationship, remains largely unknown.

In summary, it is worth noting that most of the literature examining migrant commuting distance is rooted in developed countries where market forces are well established, and residential choice is treated as an endogenous variable based on utility maximization. However, these studies lack in giving an analysis of contexts where institutional forces play a vital role in housing markets, and residential choice is more like an exogenous variable. Based on data collected from one of the largest migrant settlements in the capital city Beijing, this paper analyzes how educational attainment makes a difference in migrant commuting distances, and examines the factors shaping commuting distance for migrants with different levels of education. The following research questions are answered:

1) In a context where institutional barriers limit migrant housing choice, controlling for residential location, are there variations in migrant commuting distances by educational level?

2) Is educational attainment the strongest predictor of migrant commuting distance? For each educational level group, what are the determinants of commuting distances? How are the determinants differing across different educational levels?

Given the exogenous nature of migrant housing choice, answers to these questions will provide further understanding on how migrants with different educational attainment maximize utilities by making workplace location choices, and thus how they react to institutional barriers in the housing market.

The remainder of this paper is organized as follows: Section 2 reviews the literature examining commuting distances of both migrants and immigrants, as well as gives a brief description of institutional barriers migrants encounter in urban China. Section 3 introduces the data collection process and analytical methods. Section 4 
examines whether migrant commuting distances vary by educational level, and Section 5 explores the determinants of commuting distances among migrants with different educational attainment. The final section of this paper offers conclusions and policy implications.

\section{Understanding Migrant Commuting Distance}

\subsection{Commuting Distance of Migrants and Immigrants}

Existing studies on migrant commuting distance are mainly conducted in developed countries and focus on urban-rural migrants. Considering that China is undergoing rapid urbanization accompanied by a great number of rural-urban migrants, this paper also reviews studies on commuting distance among recently arrived immigrants in developed countries. One reason is that these immigrants share some characteristics with China's rural migrants, such as holding low socioeconomic status, making long-distance migration, and facing institutional barriers at the destination (Kain, 1968; Wyly, 1996). Another reason is while migrants in developed countries tend to make inter-county commutes, immigrants are more likely to make intra-urban commutes, which resemble the commuting patterns of China's migrants.

Among studies examining migrant commuting distance, two themes are prominent. The first theme is the relationship between the length of migration and commuting distance. In their research examining determinants of commuting distances in Toronto's commuter shed, Axisa et al. (2012b) find that recent migrants commute longer than other migrants, and commuting distance decreases as residential duration increases. Similarly, based on Canadian census data, Maoh \& Tang (2012) conclude that controlling for other variables, recent migrants are engaged in longer commutes. The second theme is the relationship between previous residential location and commuting distance, as urban-rural migrants may choose to make long commutes and still work in urban areas to maintain their former occupational levels (Green, 1999). Based on data from British census, Champion et al. (2009) find that recent migrants from the biggest cities to rural areas tend to make longer-distance commutes. Based on data collected from rural households in Britain, Findlay et al. (2001) distinguish the commuting distances between two types of migrants: "local movers" (who make short-distance moves) and "newcomers" (who moved from faraway places), and find newcomers make significantly longer commutes.

As for new immigrants, commuting behavior also co-varies with residential duration in destination countries (Tal \& Handy 2010). Empirical studies on immigrant commuting modes conclude that foreign-born immigrants are less likely to own cars and depend more on public transit, particularly in their first few years living in destination countries (Casas et al., 2004; Chatman \& Klein, 2009; Blumenberg et al., 2007; Bohon et al., 2008). However, there are fewer studies examining immigrants’ length of commutes. Based on California data, Beckham \& Goulias (2008) examine the determinants of immigrants' travel time, travel mode and departure time for work simultaneously, and identify age, residential location, immigration status and years in the US as the most important determinants. Based on the US National Household Travel Survey data, Tal \& Handy (2010) examine factors of immigrant travel behavior, and find that immigrant characteristics such as length of immigration and place of birth have less impact on miles driven per year than on travel mode.

\subsection{Job-Housing Spatial Relationships of New Immigrants}

Given the limited number of studies directly examining immigrant commuting distance, this paper also reviews research on the job-housing spatial relationships of new immigrants, which serve as a proxy for commuting distances since commuting distance is decided by residential location and workplace location. Early research shows newly arrived immigrants tend to first relocate in central-city ethnic enclaves; when their economic status improves, as the spatial assimilation theory indicates, they move to suburban areas (Preston et al., 1998; Blumenberg et al., 2007; Chatman \& Klein, 2009). In the same period, most destination cities witnessed a suburbanization of employment opportunities, especially in low-skilled occupations. The spatial mismatch hypothesis first proposed by Kain (1968) argues that low-skilled employment de-centralization and suburban housing market discrimination go some way to explain the lower wages and higher unemployment rates among central-city immigrant groups (Houston, 2005a). However, as for commuting distance, the effect of spatial mismatch is inconclusive. On the one hand, as a result of job-housing mismatch, new immigrants are supposed to commute longer than their native-born counterparts, and many studies have verified this pattern (see McLafferty \& Preston, 1997; Sultana, 2003; Preston et al., 1998). On the other hand, if spatial mismatch is severe, central-city immigrants might be constrained to a small number of local jobs, and thus shortens the commuting distances (Houston, 
2005a). The shorter commutes of immigrants are also reported by empirical studies (see Taylor \& Ong, 1995).

However, more recent studies show variations in new immigrants' settlement patterns and job distributions. As for settlement patterns, attracted by growing economic and housing opportunities in suburbs, newly arrived immigrants are more likely to locate in suburbs directly, bypassing central cities (Owusu, 1999; Blumenberg, 2009; Lo et al., 2011). As for job distribution, based on data from 60 US metropolitan areas during the period of 1980-2000, Liu \& Painter (2011) report an increasing decentralization of immigrant jobs and highlight that employment growth has occurred close to suburban areas where white people concentrate. Similarly, Chatman \& Klein (2009) report that new immigrants are likely to hold occupations (for example, construction workers, restaurant workers, and domestic workers) that are spatially dispersed in residential suburbs. As a result of the spatially dispersed employment opportunities in suburbs, suburban immigrants tend to commute longer than their central-city counterparts (Handy et al., 2008; Lo et al., 2011; Blumenberg et al., 2007).

\subsection{Institutional Context: Migrant Housing and Employment in Urban China}

Understanding migrant commuting distances in urban China must take into consideration institutional barriers in the housing market. Designed to control rural-urban migration in 1950s (Lau \& Chiu, 2013), the household registration (hukou) system is one of the major institutional barriers. Unable to change hukou from rural origins to urban destinations permanently, migrants are largely excluded from mainstream urban housing systems. Subsidized by municipalities, affordable housing such as that produced by the Economic and Comfortable Housing project and Affordable Rental Units is provided at below-market rents, but is only available to low-income households with local hukou (Wu, 2002). In addition, the soaring price of new commodity housing makes it difficult for migrants to purchase, and bank loans are often unavailable to migrants without local hukou (Zhao \& Howden-Chapman, 2010). Purchasing more affordable, older housing units in the secondary housing market also requires a local hukou or lengthy approval process (Wu, 2006).

Since urban mainstream housing is unavailable to migrants in terms of eligibility and affordability (Zhang et al., 2003), many migrants have no choice but to live in "urban villages" (Chengzhongcun), work-related dormitories, or other types of informal housing. Although notorious for chaotic land use, high population density, poor infrastructure and high crime rates, urban villages provide low-rent housing for rural migrants and somehow become migrant enclaves (Wu, 2009). However, in the view of city governments, urban villages are "eyesores" for their associated social and environmental problems, and many Chinese cities have initiated "urban village demolishment movements" in recent years. For example, in 2010, the Beijing municipal government demolished 50 urban villages where migrants were heavily concentrated, and most of them are located in the city proper. Unable to afford high rents in the city proper, migrants have to relocate to further out suburbs where some urban villages still exist, and this kind of residential relocation will likely affect migrant commuting distance.

However, in terms of migrant employment outcomes, market factors such as educational attainment seem to play a more important role than institutional factors. For example, Zhang et al. (2002) find that rural individuals with higher educational attainment are more likely to be employed in the off-farm labor market and earn higher wages. Based on the hourly wage of non-farming work, Brauw \& Rozelle (2008) find that the average return to a year of education increased from $2.3 \%$ in early 1990 s to $6.5 \%$ in 2000 . When examining determinants of wages among rural migrants, Lu \& Song (2006) conclude that education has a significant effect on wages, and they emphasize the role of education in alleviating migrant poverty. Knight et al. (2011) find that rural migrant wages have increased in recent years, and they indicate this is partly due to the increasing human capital of migrants.

Therefore, given migrants' limited housing choice and the increasing role of educational attainment in deciding their employment outcomes, it is logical to assume that educational attainment will have a significant effect on migrant commuting distance, controlling for residential location. In this paper, whether there is educational variation in migrant commuting distance is examined, and determinants of commuting distance are estimated by educational level. The results will help better understand how migrants react to institutional barriers in the housing market when making workplace location decisions.

\section{Data and Methods}

\subsection{Data}

The data is drawn from a questionnaire survey conducted in an urban village (Chengzhongcun) named Shigezhuang in Beijing. With a total migrant population of more than 45,000 by the end of 2011, Shigezhuang is now 
one of the largest migrant enclaves in Beijing. Another reason for choosing Shigezhuang is that rural migrants living here have been educationally diversified for years. According to CCTV News, since 2009 more and more migrants with tertiary education have concentrated in Shigezhuang for the relatively cheap rent and proximity to workplace locations ${ }^{1}$.

Shigezhuang is located in the northwestern suburbs of Beijing, between the 5th ring road and 6th ring road. Figure 1 shows the spatial relationship of Shigezhuang and planned employment centers of Beijing. Shigezhuang is in proximity to the Haidian technology and innovation center and the Zhongguancun science and technology center, and both are famous for their information technology industry.

Shigezhuag consists of four administrative villages, namely Shigezhuang village, East Banbidian village, West Banbidian village and Dingfuhuangzhuang village. By the end of 2011, Shigezhuang had a total area of 119 hectares, and had a total resident population of 54,417, among which 6525 were local villagers and 47,892 were migrants. Table 1 shows the changes in migrant population since 2008, and it reveals that the total migrant

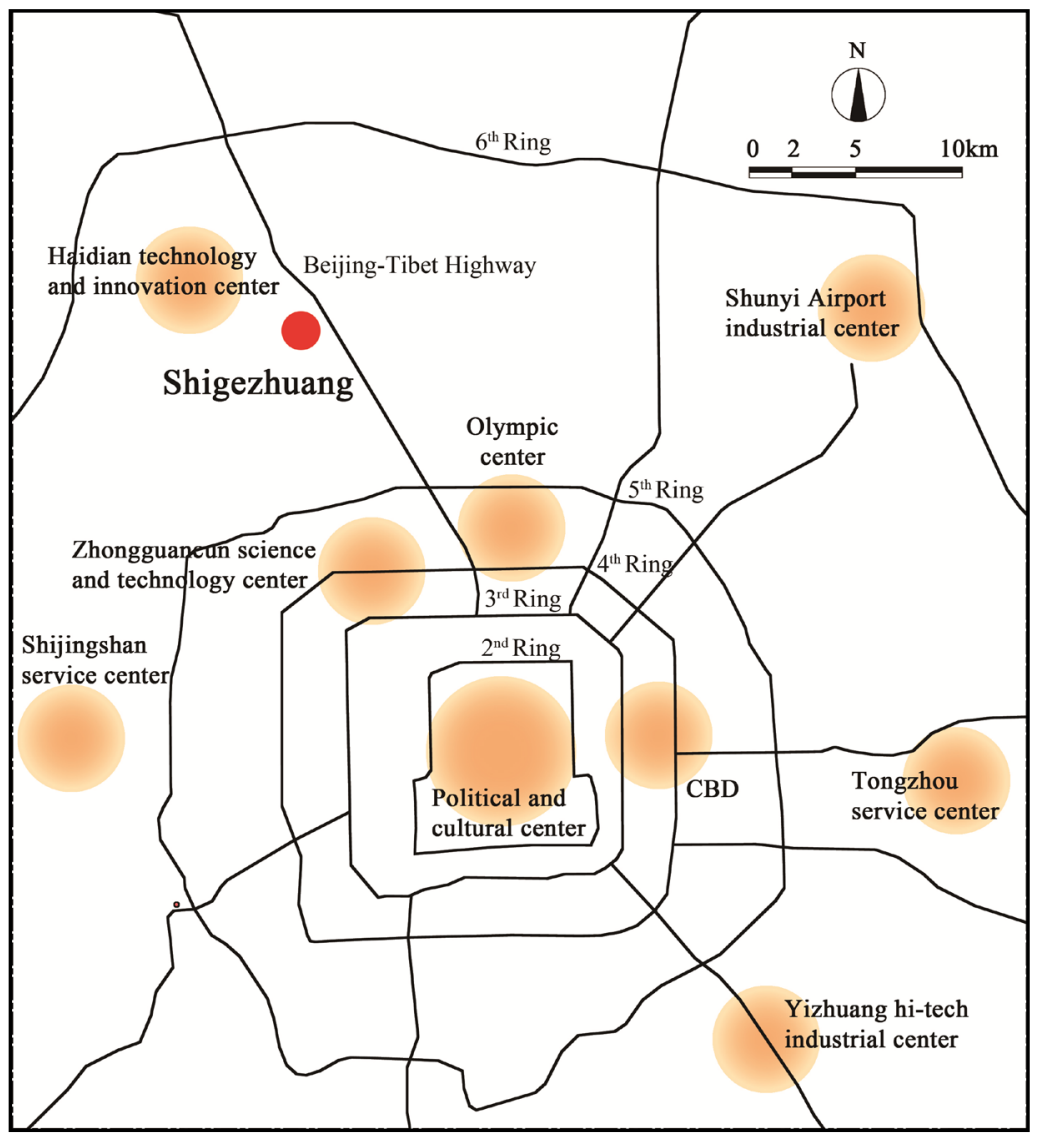

Figure 1. Spatial relationship of Shigezhuang and planned employment centers of Beijing.

Table 1. Migrant population in four administrative villages (2008-2011).

\begin{tabular}{ccccc}
\hline Area & 2008 & 2009 & 2010 & 2011 \\
\hline Shigezhuang village & 6746 & 7043 & 14,696 & 11,187 \\
East Banbidian village & 4211 & 4966 & 13,212 \\
West Banbidian village & 1646 & 1679 & 7430 & 13,560 \\
Dingfuhuangzhuang village & 7423 & 7208 & 139,334 \\
Total & 20,026 & 20,896 & 48,635 \\
\hline
\end{tabular}

\footnotetext{
${ }^{1}$ See http://news.cntv.cn/2014/07/29/VIDE1406644739143783.shtml
} 
population had doubled in 2010. As mentioned in Section 2, 2010 was the year when the Beijing government demolished 50 urban villages and saw a large number of migrants relocating to suburbs further out. Shigezhuang is one of their destinations.

We conducted a questionnaire survey on November 16-18, 2012 with distribution of 544 questionnaires, roughly $1 \%$ of the total population. The questionnaire layout of this survey consists of 4 parts: 1 ) demographic and socioeconomic information (i.e., gender, age and educational attainment); 2) employment information (i.e., occupation, industrial sector and job change information); 3) commuting information (i.e., workplace locations, commuting mode and commuting time); 4) neighborhood social bonds (i.e., numbers of friends living in the neighborhood and neighborhood activity participation). There are 36 closed-ended items in the questionnaire. Stratified random sampling procedures were used for selecting respondents. First, a certain number of questionnaires were assigned to each administrative village according to their population size. Second, we divided each administrative village into several districts and population-proportionate-to-area procedures were used to determinate the exact number of individuals to be surveyed in each district (Figure 2). A total of 498 out of the 544 questionnaires were returned. Of those returned, 461 were valid with qualified answers. Among all the respondents, only those who claimed to be employed were selected for our analysis $(\mathrm{N}=410)$.

To examine commuting distance by educational level, distinctions were made between migrants with a senior high school degree and below (defined as low educational level group), migrants with an associate degree (defined as middle educational level group) and migrants with a bachelor degree and above (defined as high educational level group). The data is excellent in that each group accounts for roughly $1 / 3$ of the total number (Figure 3). The respondents were asked to provide his or her workplace location. Commuting distance refers to the Euclidean distance between residential location and workplace location.

\subsection{Analytical Methods}

The first research question is: when residential location is controlled, are there any variations in migrant commuting distances by educational level? Commuting distances of the three educational level groups are compared by

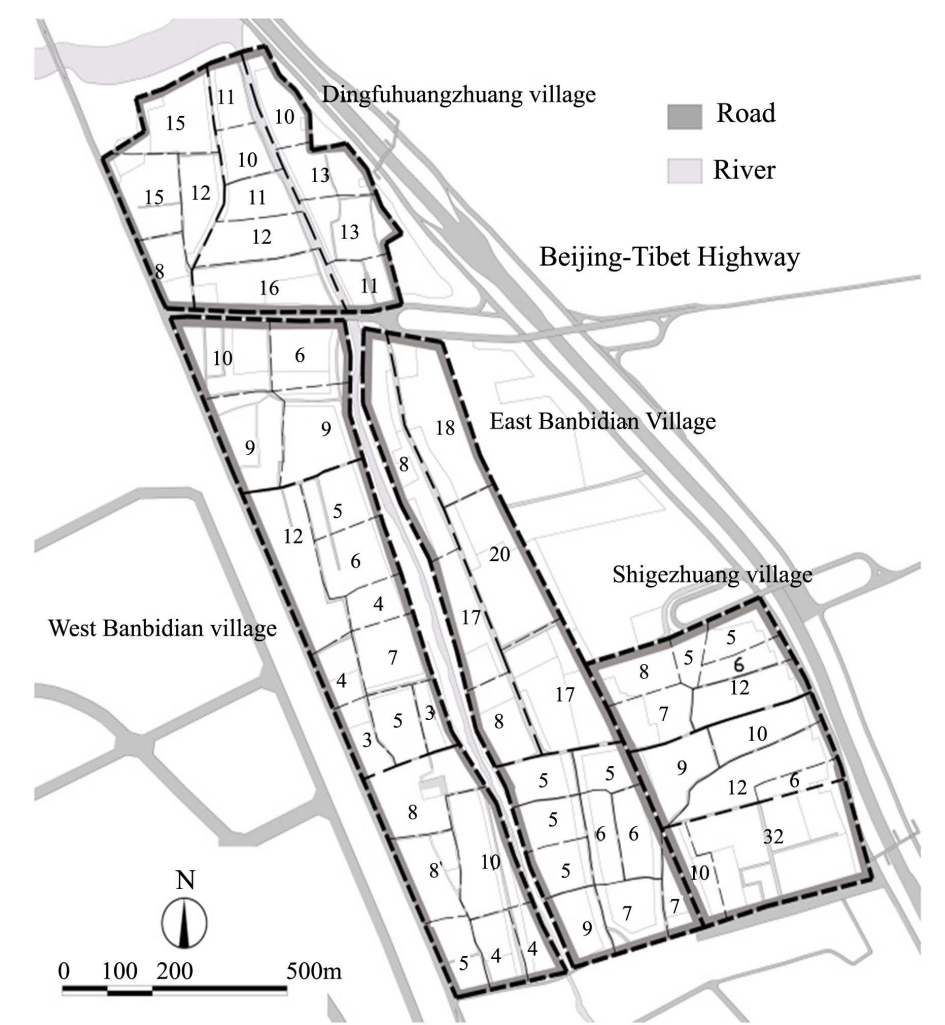

Figure 2. Distribution of 544 questionnaires (full sample). 


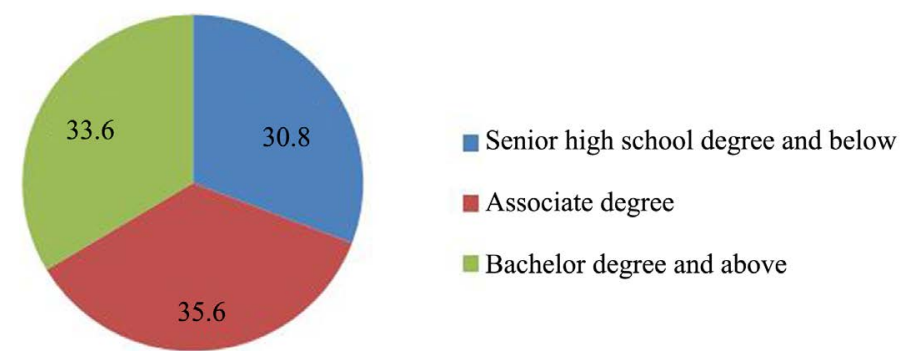

Figure 3. Distribution of respondent education attainment (percent).

using Analysis of Variance (ANOVA). Additionally, to get a better understanding of each group's commutingdistance, spatial distributions of workplace locations as well as distributions of occupations and industries are examined by educational level.

The second research question is: does educational attainment serve as the strongest predictor of commuting distance? And for each educational level group of migrants, what are the significant determinants of their commuting distances? To answer these questions, four multiple linear regression models were established. The first model includes all the respondents to examine whether educational level has the strongest effect on commuting distance, and the other three models examine determinants of commuting distance among three educational level groups, respectively.

The dependent variable is commuting distance measured in kilometers, and the independent variables are selected based on a review of the relevant literature. First, some demographic features are related to commuting distance. Women tend to make shorter commutes than men do (Blumenberg \& Manville, 2004; Blumenberg, 2004). Age influences commuting distance, largely through effects of residential preference and wage (Romani et al., 2003). Marital status is also important, especially for women commuters (Sultana, 2003). As for migrants, length of migration is positively related to commuting distance (Axisa et al., 2012ab; Maoh \& Tang, 2012). Second, work-related characteristics have influences on commuting distance. Wage and commuting distance are positively related (McLafferty \& Preston, 1997; Blumenberg \& Manville, 2004; Zenou, 2009). High-skilled workers commute longer, largely because of their higher earnings (Houston, 2005b). Job mobility and commuting distance are mutually dependent, as commuting distance changes after the relocation of a workplace (Ommeren et al., 2000). Third, commuting distance is subject to residential status. Owners tend to commute longer than tenants for it is easier for tenants to change residence (Zax \& Kain, 1991). Residential mobility factors such as decisions to move or job-related moves, is related to commuting distance (Ommeren et al., 2000; Romani et al., 2003). Fourth, commuting mode is important, for with access to automobiles the friction of commuting distance is substantially reduced (Blumenberg, 2004) ${ }^{2}$. Accordingly, 21 independent variables are selected.

\section{Education Matters: Commuting Distance, Occupation, Sector, and Workplace Location}

\subsection{Commuting Distances by Educational Level}

Overall, low educational level migrants hold the shortest commuting distances (see Table 2). In comparison, middle educational level migrants commute about 6 kilometers longer, while high educational level migrants commute about 7 kilometers longer (both are statistically significant at $p<0.01$ level). However, no significant difference is observed between commuting distances of middle educational level migrants and those of high educational level migrants.

It should be noted that all three groups of migrants commute quite short distances, considering that the average commuting distance of all urban residents in Beijing was 19.30 kilometers in $2012^{3}$ (Table 2). According to Gottlieb \& Lentnek (2001), there are two explanations for the observed short commuting distances. One is that migrants can find skill-matched jobs in surrounding areas easily, and thus they do not need to make long commutes. The other is the skill-matched jobs nearby are so few that migrants are unwilling to make long commutes due to their low economic status. As a result, migrants are constrained to local informal sectors. To further un

\footnotetext{
${ }^{2}$ However, commuting mode is not included in regression models for several reasons. First, less than $2 \%$ of the respondents reported to commute by private vehicles. Second, the residential location is fixed so there is not a public transit service difference among respondents. Third, the costs of public transit are quite low in 2012, for it takes about 0.06 dollars for bus ride and about 0.3 dollars for subway ride. ${ }^{3}$ Data source: http://sh.house.sina.com.cn/news/cityill/index.shtml
} 
Table 2. Average commuting distances: analysis of variance by educational level.

\begin{tabular}{ccccc}
\hline \multirow{2}{*}{ Educational level } & Average & $\begin{array}{c}\text { Compared with low educa- } \\
\text { tional level }(\mathrm{km})\end{array}$ & $\begin{array}{c}\text { Difference from middle } \\
\text { educational level }(\mathrm{km})\end{array}$ & $\begin{array}{c}\text { Difference from high edu- } \\
\text { cational level }(\mathrm{km})\end{array}$ \\
\cline { 2 - 5 } & commuting distance $(\mathrm{km})$ & - & $-6.07^{* * *}$ & $-6.83^{* * *}$ \\
\hline Low educational level & 6.85 & $6.07^{* * *}$ & - & -0.76 \\
Middle educational level & 12.93 & $6.83^{* * *}$ & 0.76 & - \\
$\begin{array}{c}\text { High educational level } \\
\begin{array}{c}\text { Beijing's average for local } \\
\text { residents }\end{array}\end{array}$ & 13.69 & - & - & - \\
\hline
\end{tabular}

Note: $-=$ not applicable; $\stackrel{* * *}{\mathrm{p}}<0.01$.

derstand the dynamics of migrant commuting distance, this paper examines distributions of occupations, industrial sectors, and workplace locations by educational level.

\subsection{Occupations by Educational Level}

Table 3 shows distributions of occupations by educational level. The results are consistent with the general belief that workers with higher educational attainment tend to be involved in higher occupation employment that operates in a city-wide labor market. As for low educational level migrants, a high proportion of them are engaged in self-employment (33\%). As indicated by other scholars (Skeldon, 1997; Light, 2004), these migrants usually participate in local informal sectors serving the huge migrant population, such as running restaurants, small inns, grocery stores and barbershops ${ }^{4}$. Having no access to the housing subsidies (in the form of contribution to housing provident fund) provided by formal enterprises, they also cannot apply for urban public rental housing, which in turn puts them at a disadvantage. Meanwhile, middle and high educational level migrants are engaged in occupations which are more likely to operate in a city-wide labor market: for middle educational level migrants, most of them are technicians (40\%) or clerks (13\%); for the high educational level migrants, the proportion of technicians is even higher (48\%), followed by management positions (19\%).

\subsection{Industrial Sectors by Educational Level}

Table 4 shows distributions of industrial sectors by educational level. Considerable differences are observed among the three groups. As for low educational level migrants, most of them (24\%) are engaged in such sectors as wholesale, retail, hotels and catering services, and residential service. They serve the migrant population as well as local residents living nearby. In addition, $16 \%$ of low educational level migrants are engaged in construction and manufacturing, and most of them work in local village collective-owned factories. As for middle and high educational level migrants, they are more likely to take jobs in information transmission, computer service, and software. As mentioned in Section 3, Shigezhuang is in proximity to city-wide IT employment centers (see Figure 1). That may well explain why so many middle and high educational level migrants work in IT-related industries. However, short of skill, low educational level migrants are unable to take advantages of this employment proximity.

\subsection{Workplace Locations by Educational Level}

Figure 4 shows spatial distributions of migrant workplace locations by educational level. For each group, there seem to be two employment centers. As for low educational level migrants, the employment centers are the Shigezhuang and Huilongguan residential areas. Although the number of non-farming jobs in Shigezhuang is not expected to be high according to the official economic census, $41 \%$ of low educational level migrants work there engaged in informal sector labor providing services for the residential population, or working in the local village collective-owned factories. Sixteen percent of low educational level migrants work in Huilongguan, which is not far from Shigezhuang. With the total residential population of about 300 thousand, Huilongguan is one of the largest suburban residential districts in Beijing and is in great demand of low-skilled workers such as sales people and construction workers. Middle and high educational level migrants share the same employment

\footnotetext{
${ }^{4}$ Since urban village is defined as an informal settlement in China, most of the businesses in urban villages do not have legal statuses.
} 
Table 3. Distributions of occupations by educational level (percent).

\begin{tabular}{cccc}
\hline Occupations & low educational level & middle educational level & high educational level \\
\hline Self-employment & 33.3 & 11.6 & 3.4 \\
Service & 14.6 & 11.6 & 7.4 \\
Technician & 21.1 & 39.5 & 48.0 \\
Teacher & 1.6 & 4.1 & 2.0 \\
Management & 7.3 & 8.8 & 8.9 \\
Clerk & 4.9 & 12.9 & 2.0 \\
Manual worker & 8.1 & 3.4 & 10.2 \\
Other & 9.1 & 8.1 & 10.9 \\
\hline
\end{tabular}

Table 4. Distributions of industrial sectors by educational level (percent).

\begin{tabular}{cccc}
\hline Industries & low educational level & middle educational level & high educational level \\
\hline Financial and real estates & 0.7 & 4.3 & 4.5 \\
Construction and manufacturing & 15.5 & 14.0 & 11.0 \\
$\begin{array}{c}\text { Production and supply of power, gas and water; transports, } \\
\text { warehousing and post; sanitation, social security and social welfare }\end{array}$ & 5.6 & 4.9 & 3.2 \\
$\begin{array}{c}\text { Information transmission, computer service and software } \\
\quad \begin{array}{l}\text { Wholesale and retail; hotels and catering services; } \\
\text { residential service }\end{array}\end{array}$ & 14.1 & 34.1 & 5.2 \\
$\begin{array}{c}\text { Culture, sports and entertainment; education; scientific research, } \\
\text { technical service and geological survey } \\
\text { Other }\end{array}$ & 23.9 & 11.0 & 18.1 \\
\hline
\end{tabular}

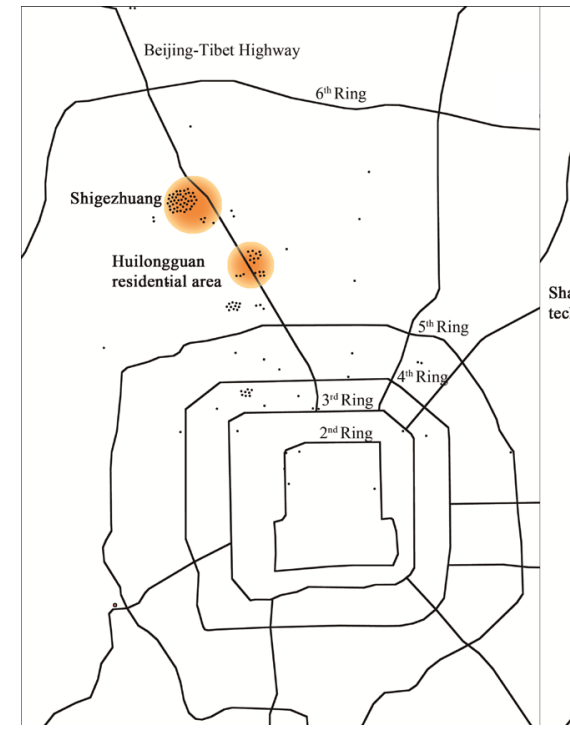

(a)

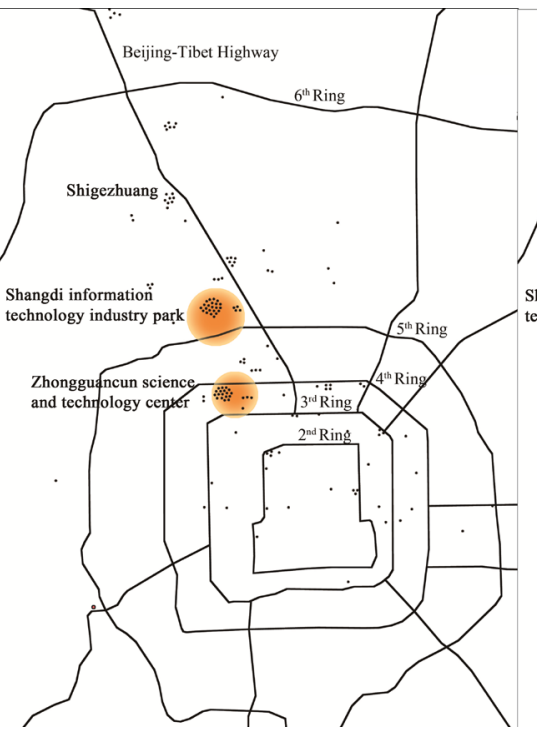

(b)

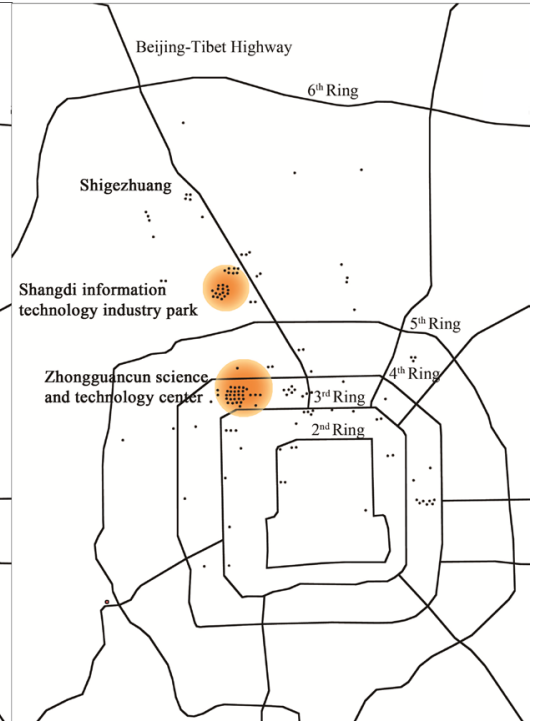

(c)

Figure 4. Spatial distributions of workplace locations by educational level. (a) Low educational level; (b) middle educational level; (c) high educational level. 
centers: the Shangdi information technology center and the Zhongguancun science and technology center, and both of them are city-wide IT employment centers.

Examining distributions of migrant occupations, industrial sectors, and workplace locations by educational level, we are able to understand how educational attainment affects commuting distance. For low educational level migrants, their average commuting distance is the shortest among the three groups, largely because there are not many low-skilled jobs nearby and thus they are constrained to local informal sectors. For middle and high educational level migrants, thanks to Shigezhuang's proximity to city-wide information industry centers, they are able to take skill-matched jobs while enjoying relatively short commuting distances. Therefore, when the residential location is controlled, higher educational attainment migrants are more able to take skill-matched jobs operating at a city-wide labor market.

\section{Predicting Commuting Distances by Educational Level}

\subsection{For All Respondents}

Before examining determinants of commuting distance by educational level, to test whether educational attainment is the strongest predictor of migrant commuting distance, a multiple linear regression model for all respondents is established (see the second column of Table 5). Since all coefficients reported in Table 5 are standardized, the relative importance of each independent variable in determining commuting distance can be identified.

First, the results confirm the hypothesis: compared with other independent variables, educational attainment acts as the most important determinant of migrant commuting distance. To be specific, migrants who have received more years of education commute significantly longer than their lower educational attainment counter parts. Positively related to human capital, educational attainment is often seen as an indicator of market forces. In other words, controlling for residential location, market forces play the most important role in determining migrant workplace locations. This result is to some extent surprising, considering that China's migrants have long been known for being subject to institutional constraints in terms of both housing (Wu, 2002; Wu, 2006) and employment (Wong, Chang, \& He 2007; Knight, Deng, \& Li 2011). However, this result is consistent with the hypothesis established among urban residents in developed countries that high-skilled workers have a higher degree of spatial mobility within a metropolitan area (Houston, 2005b).

Therefore, policies aimed at increasing rural migrant access to higher education are helpful, for they enable migrants to participate in labor markets operating at a larger geographic scale. For low educational level migrants, with low skill and low economic status, long-distance commuting is not a desirable option. As a result, where they work largely depends on where they live. Since migrant enclaves are recognized as informal settlements by the Chinese state, their fate is uncertain. In case of a teardown, low educational level migrants may lose both their shelters and their jobs. Therefore, they are the most disadvantaged in the context of China's institutional barriers. Meanwhile, migrants who have received tertiary education (middle and high educational level migrants) are more able to take jobs that operate in a citywide labor market. It seems that when they are forced to relocate to further out suburban migrant enclaves, they may choose to make long-distance commutes to maintain their former occupational levels. Therefore, they are less disadvantaged compared with their lower educational attainment counterparts.

Second, besides educational attainment, two work-related characteristics, namely occupation and industrial sector, also have relatively strong effects on migrant commuting distance. The effect of occupation is in accordance with the common hypothesis that individuals holding higher occupations commute longer: compared with migrants who are self-employed, those who take jobs as service workers, technicians and managements commute significantly longer. As mentioned in Section 4, the self-employed migrants tend to run small local businesses serving the huge amount of residential population, and they are at a disadvantage since their businesses often don't have legal status. Conversely, higher-skilled occupations (service workers, technicians and members of management) require longer commuting distances, and it can be inferred that longer commutes are compensated by higher wages (Zenou, 2009; Blumenberg, 2004).

As for industrial sector, the baseline category is "financial, real estate and other". Most of the respondents engaged in financial and real estate work in the CBD with the observed longest commuting distance of about 27 kilometers. This explains why compared with this baseline category, all other industries display negative impacts on commuting distance. The results show that migrants engaged in "wholesale, retail, hotels and catering 
Table 5. Effects of demographic features, work-related characteristics, and residential features on migrant commuting distance.

\begin{tabular}{|c|c|c|c|c|c|}
\hline & & $\begin{array}{l}\text { All } \\
\text { respondents }\end{array}$ & $\begin{array}{l}\text { Low educational } \\
\text { level group }\end{array}$ & $\begin{array}{l}\text { Middle educational } \\
\text { level group }\end{array}$ & $\begin{array}{l}\text { High educational } \\
\text { level group }\end{array}$ \\
\hline \multicolumn{6}{|c|}{ Demographic features } \\
\hline MALE & Male & 0.01 & 0 & 0.04 & 0.02 \\
\hline AGE $>29$ & Aged 29 years and older & 0.03 & 0.16 & 0.03 & -0.05 \\
\hline MARRIED & $\begin{array}{l}\text { Married and co-residence with } \\
\text { spouse }\end{array}$ & -0.04 & -0.14 & $-0.18^{*}$ & 0.09 \\
\hline MIG $<2$ & $\begin{array}{c}\text { Length of migration is less than } 2 \\
\text { years }\end{array}$ & -0.02 & -0.09 & 0.09 & -0.16 \\
\hline Education & Years of education & $0.28^{* * *}$ & - & - & - \\
\hline \multicolumn{6}{|c|}{ Work-related characteristics } \\
\hline INC $>960$ & Monthly income > 960 US Dollars & -0.07 & 0.02 & 0.08 & -0.13 \\
\hline JOBCHANGE & $\begin{array}{l}\text { Has ever changed job since moved to } \\
\text { the current residence }\end{array}$ & 0.07 & $0.17^{*}$ & 0.03 & -0.01 \\
\hline \multicolumn{6}{|c|}{ Baseline category for Occupation: self-employed and other } \\
\hline SERVICE & Service worker & $0.12^{* *}$ & $0.18^{*}$ & 0.1 & 0.04 \\
\hline TECH & Technician & $0.13^{*}$ & $0.24^{* *}$ & $0.26^{*}$ & -0.12 \\
\hline TEACHER & Teacher & -0.02 & 0.08 & -0.07 & -0.12 \\
\hline MANAG & Management & $0.16^{* * *}$ & 15 & $0.24^{* *}$ & 0.01 \\
\hline CLERK & Clerk & 0.08 & 0.03 & $0.21^{* *}$ & -0.06 \\
\hline MAWORK & Manual worker & -0.07 & -0.07 & -0.07 & 0.08 \\
\hline \multicolumn{6}{|c|}{$\begin{array}{l}\text { Baseline category for Industrial sector: } \\
\text { financial \& real estates and other }\end{array}$} \\
\hline CONMAN & Construction and manufacturing & -0.06 & -0.05 & -0.18 & -0.15 \\
\hline PROTRANSA & $\begin{array}{l}\text { Production and supply of power, gas } \\
\text { and water; transports, warehousing } \\
\text { and post; sanitation, social security } \\
\text { and social welfare }\end{array}$ & -0.05 & 0.02 & -0.11 & -0.12 \\
\hline INFO & $\begin{array}{l}\text { Information transmission, computer } \\
\text { service and software }\end{array}$ & -0.06 & 0.13 & $-0.26^{*}$ & $-0.25^{*}$ \\
\hline WHHORE & $\begin{array}{l}\text { Wholesale and retail; hotels and } \\
\text { catering services; residential service }\end{array}$ & $-0.22^{* * *}$ & $-0.21^{* *}$ & $-0.24^{* *}$ & $-0.27^{* * *}$ \\
\hline CUEDUTEC & $\begin{array}{l}\text { Culture, sports and entertainment; } \\
\text { education; scientific research, } \\
\text { technical service and } \\
\text { geological survey }\end{array}$ & $-0.14^{* *}$ & -0.08 & -0.15 & $-0.28^{* *}$ \\
\hline \multicolumn{6}{|c|}{ Residential features } \\
\hline RENTER & Renters & $-0.09^{*}$ & -0.03 & $-0.25^{*}$ & -0.13 \\
\hline MOBILITY & $\begin{array}{c}\text { Have ever made residential moves in } \\
\text { Beijing }\end{array}$ & 0.04 & 0.08 & 0.07 & 0.06 \\
\hline MOBILITY-JOB & $\begin{array}{l}\text { Have ever made job-related } \\
\text { residential moves in Beijing }\end{array}$ & $-0.15^{* * *}$ & -0.15 & $-0.18^{*}$ & $-0.22^{* *}$ \\
\hline $\mathrm{N}$ & & 410 & 123 & 146 & 141 \\
\hline $\mathrm{R}^{2}$ & & 0.24 & 0.29 & 0.2 & 0.21 \\
\hline
\end{tabular}

"Standardized coefficient is significant at 0.1 level. ${ }^{* *}$ Standardized coefficient is significant at 0.05 level. ${ }^{* * *}$ Standardized coefficient is significant at 0.01 level. —: not applicable. 
services, and residential service” hold significantly shorter commuting distances, largely because they are involved in local business serving the residential population. Compared with them, migrants engaged in "culture, sports, entertainment, education, scientific research, technical service and geological survey" commute significantly longer, again suggesting the differences between migrants constrained to local sectors and migrants engaged in city-wide labor market.

Third, two residential features are important: being a renter and having ever made job-related residential moves in Beijing have significant effects on migrant commuting distance. The former is in accordance with the widely accepted hypothesis that it is easier for renters to change residence (Zax \& Kain, 1991), and as a result renters tend to enjoy shorter commuting distances than owners. In addition, migrants who have ever made job-related moves may view job-housing spatial proximity as very important and are more likely to live close to the workplace, leading to shorter commuting distances.

\subsection{Models by Educational Level}

Given the important role of educational attainment in explaining migrant commuting distance, we then establishes three multiple linear regression models (one for each educational level group) to see how determinants of migrant commuting distance vary by educational level (see the third to fifth columns in Table 5).

As for low educational level migrants, the most important factor is occupation: compared with being self-employed, being a technician has the strongest positive effect on commuting distance, followed by being a service worker. Industrial sector also serves as an important factor: migrants engaged in "wholesale, retail, hotels and catering services, and residential service" commute significantly shorter than migrants engaged in "financial, real estate and other". It is worth noting that a job change also turns to be a significant factor: migrants who have ever changed jobs since moving to their current residence have longer commuting distances than those have not changed jobs. This result indicates that although low educational level migrants are forced to live in suburban areas, not all of them are constrained to local informal sectors. Instead, many low educational level migrants are still making efforts to search for jobs in more skilled occupations and industrial sectors, which lead to longer commuting distances.

As for middle educational level migrants, occupation and industrial sector continue to be the two most important factors explaining commuting distance: compared with being self-employed, being a technician, being in management and being a clerk display positive impacts on commuting distance; compared with migrants engaged in "financial, real estate and other", migrants engaged in "information transmission, computer service and software" and "wholesale, retail, hotels and catering services, and residential service" commute significantly shorter distances. In addition to being a renter and having ever made job-related residential moves, being married and co-residence with a spouse are also negatively related to commuting distance. This result is consistent with the common belief that once married, individual's spatial mobility is more or less constrained by domestic responsibilities.

As for high educational level migrants, the strongest predictor of commuting distance is industrial sector: compared with migrants engaged in "financial, real estate and other", migrants engaged in "information transmission, computer service and software", "wholesale, retail, hotels and catering services, and residential service" and "culture, sports, entertainment, education, scientific research, technical service and geological survey" commute much shorter distances and have a similar commuting distance with one another. In addition, having ever made job-related residential moves has negative effect on commuting distance. However, occupation and housing tenure do not show significant effects among high educational level migrants.

When comparing determinants of commuting distance among the three educational levels, it can be concluded that low educational level migrants are more constrained in terms of job-housing spatial relationship. The reasons are as follows:

First, although $52 \%$ of low educational level migrants have made job-related residential moves, whether they have moved does not affect their current commuting distance significantly. In contrast, their higher educational attainment counterparts who have made job-related residential moves enjoy significantly shorter commuting distances, indicating their higher abilities to strike a balance between residential and workplace locations. The main explanation may be that due to their low economic status, low educational level migrants tend to live in urban villages, which are famous for low rent and are identified as informal settlements by the Chinese state. In recent years, governments have begun to tear down urban villages gradually, and migrant tenants are forced to 
relocate. As a result, the unpredictable involuntary moves make it difficult for low educational level migrants to maintain their former job-housing proximity.

Second, for low educational level migrants, those who have changed jobs since moving to their current residence commute significantly longer, while this phenomenon is not observed among middle and high educational level migrants. This result implies that these low educational level migrants are giving primacy to residential location, and it is likely after they settle down that they begin to search for employment opportunities. Some of them are constrained to nearby informal sectors with short commuting distances, while others are still trying to find jobs in the city-wide labor market with longer commuting distances. This result highlights the importance of providing migrants, especially those with low educational attainment, shelters near skill-matched employment centers, for their employment choices largely depend on their residential locations.

However, it is surprising that some widely accepted determinants of migrant/immigrant commuting distance in developed countries show no significant effect in this study, neither in the overall model nor in models for the three educational level groups individually.

First, it is previously argued that length of migration/immigration affects commuting distance significantly (Beckham \& Goulias, 2008; Maoh \& Tang, 2012; Tal \& Handy, 2010), and as length of residence in destinations increases, migrants'/immigrants' commuting behaviors will resemble those of local residents. However, in the current study, length of migration shows no significant effect. As migrants' residential duration in Beijing increases, their commuting distances do not tend to vary. A main reason is that due to institutional constraints, migrants in China behave like circular migrants. Although many cities now provide migrants with temporary registration and it is much easier for migrants to stay in cities for an extended period of time (Wu \& Wang, 2014), failing to change hukou from rural origins to urban destinations permanently, most migrants don't have access to many urban amenities and are expected to go back to their rural hometowns eventually. As a result, viewing cities as temporary residence and not expecting to settle down permanently, a longer length of migration does not necessarily mean that migrants will change their commuting behaviors or behave more like local residents.

Second, unlike the common belief that women usually commute shorter distances than men do (Blumenberg \& Manville, 2004; Blumenberg, 2004), gender does not display a significant impact in this study. The possible explanation is that since most migrants cannot settle down permanently in cities and are expected to go back to rural hometowns, they usually leave their children in rural homes in the charge of grandparents. And this kind of circular migration is motivated by economic factors and the purpose of working in cities is to earn more wages (Wen \& Wang, 2009; Fan, 2011). As a result, female migrants engage themselves in working as much as male migrants do, and this explains why there is no gender variation in migrant commuting distances.

\section{Conclusions and Policy Implications}

Given the exogenous nature of rural migrants' housing choices in urban China, examining migrant commuting distances helps understand their job-housing spatial relationships, and thus sheds light upon how they react to institutional barriers in the housing market when making workplace location decisions. In view of the increasing role of educational attainment in determining migrant employment outcomes, this paper examines the role of educational attainment in migrant commuting distances.

The results highlight the fact that there is significant variation in migrant commuting distances by educational level: migrants with low educational attainment (senior high school degree and below) commute significantly shorter distances than their counterparts with higher educational attainment. In addition, when residential location is controlled, with higher educational attainment migrants are more able to take skill-matched jobs operating in a city-wide labor market. On the one hand, due to a lack of low-skilled jobs nearby, low educational attainment migrants are to some extent constrained to nearby informal sectors serving the residential population, or they work in local collective-owned factories. On the other hand, with higher skill, migrants with middle educational attainment (associate degree) and high educational attainment (bachelor degree and above) are more likely to work at the nearby city-wide information technology centers while enjoying shorter commuting distances than average urban residents.

This paper also finds years of education, an indicator of market forces, serves as the strongest predictor of migrant commuting distance. In addition, occupation, industrial sector, housing tenure and job-related residential moves have significant effects on commuting distance. When comparing the determinants among migrants 
of three educational levels, this paper concludes that low educational level migrants are more constrained in terms of the job-housing spatial relationship. With low human capital and low economic status, they usually fail to obtain job-housing proximity through residential moves. In addition, low educational level migrants are more likely to give primacy to residential choices and their employment choices largely depend on their residential locations. Meanwhile, migrants who have received tertiary education (middle and high educational level migrants) have a greater ability to find a balance between residential and workplace locations, largely because of their higher degree of spatial mobility.

Moreover, as a result of institutional barriers, migrants in urban China behave like circular migrants: constrained by the household registration system (hukou), most of them can't expect to settle down permanently in host cities. And this well explains why some widely accepted determinants of migrant/immigrant commuting distance in developed countries such as length of migration and gender show no significant effect in this study.

Therefore, in considering the job-housing spatial relationship, does increasing rural migrant access to higher education serve as a good strategy to help them better integrate into urban society? The answer is yes in that migrants who have received tertiary education are a privileged group: they are more able to participate in a city-wide labor market, and they have more of a chance to balance residential and workplace locations. The answer is no in that despite educational variations in commuting distances, all migrants are still faced with institutional barriers which largely exclude them from settling down in host cities. In addition, the recent demolishment of urban villages has forced them to relocate to further out suburbs. As a result, as the length of migration increases, migrant commuting behavior will not resemble those of local residents, suggesting there is hardly any process of assimilation for rural migrants in urban China.

In order to help migrants better integrate into urban society, enabling them to receive tertiary education is not enough, and other policies should be carried out. First, it is observed that while migrants are forced to move to further out suburbs, their workplace locations largely remain in central cities. Therefore, policies aiming at providing affordable shelter near employment centers might help. Second, unable to transform their household registration (hukou) officially, migrants are expected to go back to rural hometowns eventually. As a result, they may sacrifice their living standards in the host city that is seen as a temporary residence. In the near future, policies should provide better-educated migrants more opportunities to gain urban household registrations.

\section{Acknowledgements}

This research is funded by the key project of National Science Foundation of China (41598400165) "Dynamic model construction and threshold value calculation on the stress interaction of urbanization and ecological environment in the area of mage-urban agglomeration”. We also acknowledge funding from China Scholarship Council. Special thanks to Dr. Sushama Wagh for technical support and guidance.

\section{References}

Axisa, J. J., Scott, D. M., \& Newbold, K. B. (2012a). Factors Influencing Commute Distance: A Case Study of Toronto's Commuter Shed. Journal of Transport Geography, 24, 123-129. http://dx.doi.org/10.1016/j.jtrangeo.2011.10.005

Axisa, J. J., Newbold, K. B., \& Scott, D. M. (2012b). Migration, Urban Growth and Commuting Distance in Toronto’s Commuter Shed. Area, 44, 344-355. http://dx.doi.org/10.1111/j.1475-4762.2012.01097.x

Beckham, J. D., \& Goulias, K. G. (2008). Immigration, Residential Location, Car Ownership, and Commuting Behavior: A Multivariate Latent Class Analysis from California. Transportation, 35, 655-671.

http://dx.doi.org/10.1007/s11116-008-9172-x

Blumenberg, E. (2004). En-Gendering Effect Planning: Spatial Mismatch, Low-Income Women, and Transportation Policy. Journal of the American Planning Association, 70, 269-281. http://dx.doi.org/10.1080/01944360408976378

Blumenberg, E. (2009). Moving in and Moving Around: Immigrants, Travel Behavior, and Implications for Transport Policy. Transportation Letters, 1, 169-180. http://dx.doi.org/10.3328/TL.2009.01.02.169-180

Blumenberg, E., \& Manville, M. (2004). Beyond the Spatial Mismatch: Welfare Recipients and Transportation Policy. Journal of Planning Literature, 19, 182-205. http://dx.doi.org/10.1177/0885412204269103

Blumenberg, E., Donahue, M., Handy S., Lovejoy, K., Rodier, C., Shaheen, S., \& Volker, J. (2007). Travel of Diverse Populations: Literature Review. Institute of Transportation Studies.

Bohon, S. A., Stams, K., \& Atiles, J. H. (2008). Transportation and Migrant Adjustment in Georgia. Population Research and Policy Review, 27, 273-291. http://dx.doi.org/10.1007/s11113-008-9075-8

Brauw, A., \& Rozelle, S. (2008). Reconciling the Returns to Education in Off-Farm Wage Employment in Rural China. Re- 
view of Development Economics, 12, 57-71.

Casas, J., Arce, C., \& Frye, C. (2004). Latino Immigration and Its Impact on Future Travel Behavior. National Household Travel Survey Conference: Understanding Our Nation's Travel, Washington DC, October.

Champion, T., Coombes, M., \& Brown D. L. (2009). Migration and Longer-Distance Commuting in Rural England. Regional Studies, 43, 1245-1259. http://dx.doi.org/10.1080/00343400802070902

Chatman, D. G., \& Klein, N. (2009). Immigrants and Travel Demand in the United States. Public Works Management \& Policy, 13, 312-327.

Dieleman, F. M. (2001). Modelling Residential Mobility: A Review of Recent Trends in Research. Journal of Housing and the Built Environment, 16, 249-265. http://dx.doi.org/10.1023/A:1012515709292

Fan, C. C. (2011). Settlement Intention and Split Households: Findings from a Survey of Migrants in Beijing’s Urban Villages. The China Review, 11, 11-42.

Findlay, A. M., Stockdale, A., Findlay, A., \& Short, D. (2001). Mobility as a Driver of Change in Rural Britain: An Analysis of the Links between Migration, Commuting and Travel to Shop Patterns. International Journal of Population Geography, 7, 1-15. http://dx.doi.org/10.1002/ijpg.201

Gottlieb, P. D., \& Lentnek, B. (2001). Spatial Mismatch Is Not Always a Central-City Problem: An Analysis of Commuting Behavior in Cleveland, Ohio, and Its Suburbs. Urban Studies, 38, 1161-1186. http://dx.doi.org/10.1080/00420980120051701

Green, A. (1999). Employment Opportunities and Constraints Facing In-Migrants to Rural Areas in England. Geography, 84, 34-44.

Gu, C., Sheng, M., \& Hu, L. (2015). Chapter 5: Spatial Characteristics and New Changes of the “Ant Tribe” Urban Village in Beijing: Cases Studies of Tangjialing and Shigezhuang. In T. C. Wong, S. S. Han, \& H. M. Zhang (Eds.), Population Mobility, Urban Planning and Management in China (pp. 73-93). Cham, Switzerland: Springer International Publishing. http://dx.doi.org/10.1007/978-3-319-15257-8_5

Handy, S., Blumenberg, E., Donahue, M., Lovejoy, K., Rodier, C., Shaheen, S., Shiki, K., \& Song, L. (2008). Travel Behavior of Mexican and Other Immigrant Groups in California. Berkeley Planning Journal, 21, 1-24.

Houston, D. S. (2005a). Methods to Test the Spatial Mismatch Hypothesis. Economic Geography, 81, 407-434. http://dx.doi.org/10.1111/j.1944-8287.2005.tb00281.x

Houston, D. S. (2005b). Employability, Skills Mismatch and Spatial Mismatch in Metropolitan Labor Markets. Urban Studies, 42, 221-243. http://dx.doi.org/10.1080/0042098042000316119

Kain, J. F. (1968). Housing Segregation, Negro Employment, and Metropolitan Decentralization. The Quarterly Journal of Economics, 82, 175-197. http://dx.doi.org/10.2307/1885893

Knight, J., Deng, Q., \& Li, S. (2011). The Puzzle of Migrant Labor Shortage and Rural Surplus in China. China Economic Review, 22, 585-600. http://dx.doi.org/10.1016/j.chieco.2011.01.006

Lau, J. C., \& Chiu, C. C. H. (2013). Dual-Track Urbanization and Co-Location Travel Behavior of Migrant Workers in New Towns in Guangzhou. China Cities, 30, 89-97. http://dx.doi.org/10.1016/j.cities.2011.12.011

Light, D. W. (2004). From Migrant Enclaves to Mainstream: Conceptualizing Informal Economic Behavior. Theory and Society, 33, 705-737. http://dx.doi.org/10.1023/B:RYSO.0000049193.32984.c2

Liu, C. Y., \& Painter, G. (2011). Immigrant Settlement and Employment Suburbanization in the US: Is There a Spatial Mismatch? Urban Studies, 49, 979-1002. http://dx.doi.org/10.1177/0042098011405695

Lo, L., Shalaby, A., Eng, P., \& Alshalalfah, B. (2011). Relationship between Immigrant Settlement Patterns and Transit Use in the Greater Toronto Area. Journal of Urban Planning and Development, 137, 470-476. http://dx.doi.org/10.1061/(ASCE)UP.1943-5444.0000080

Lu, Z., \& Song, S. (2006). Rural-Urban Migration and Wage Determination: The Case of Tianjin, China. China Economic Review, 17, 337-345. http://dx.doi.org/10.1016/j.chieco.2006.04.007

Maoh, H., \& Tang, Z. (2012). Determinants of Normal and Extreme Commute Distance in a Sprawled Midsize Canadian City: Evidence from Windsor, Canada. Journal of Transportation Geography, 25, 50-57. http://dx.doi.org/10.1016/j.jtrangeo.2012.07.003

Martin, R. W. (2001). Spatial Mismatch and Costly Suburban Commutes: Can Commuting Subsidies Help? Urban Studies, 38, 1305-1318. http://dx.doi.org/10.1080/00420980120061034

McLafferty, S., \& Preston, V. (1997). Gender, Race, and the Determinants of Commuting: New York in 1990. Urban Geography, 18, 192-212. http://dx.doi.org/10.2747/0272-3638.18.3.192

Ommeren, J., Rietveld, P., \& Nijkamp, P. (2000). Job Mobility, Residential Mobility and Commuting: A Theoretical Analysis Using Search Theory. The Annals of Regional Science, 34, 213-232. http://dx.doi.org/10.1007/s001689900004

Owusu, T. Y. (1999). Residential Patterns and Housing Choices of Ghanaian Immigrants in Toronto, Canada. Housing Stu- 
dies, 14, 77-97. http://dx.doi.org/10.1080/02673039983019

Preston, V., McLafferty, S., \& Liu, X. F. (1998). Geographical Barriers to Employment for American-Born and Immigrant Workers. Urban Studies, 35, 529-545. http://dx.doi.org/10.1080/0042098984899

Romani, J., Surinach, J., \& Artiis, M. (2003). Are Commuting and Residential Mobility Decisions Simultaneous? The Case of Catalonia, Spain. Regional Studies, 37, 813-826. http://dx.doi.org/10.1080/0034340032000128730

Skeldon, R. (1997). Rural-to-Urban Migration and Its Implications for Poverty Alleviation. Asia-Pacific Population Journal, 12, 3-16.

Sultana, S. (2003). Commuting Constraints of Black Female Workers in Atlanta: An Examination of the Spatial Mismatch Hypothesis in Married-Couple, Dual-Earner Households. Southeastern Geographer, 43, 249-259.

http://dx.doi.org/10.1353/sgo.2003.0000

Tal, G., \& Handy, S. (2010). Travel Behavior of Immigrants: An Analysis of the 2001 National Household Transportation Survey. Transport Policy, 17, 85-93. http://dx.doi.org/10.1016/j.tranpol.2009.11.003

Taylor, B. D., \& Ong, P. M. (1995). Spatial Mismatch or Automobile Mismatch? An Examination of Race, Residence and Commuting in US Metropolitan Areas. Urban Studies, 32, 1453-1473. http://dx.doi.org/10.1080/00420989550012348

Wen, M., \& Wang, G. (2009). Demographic, Psychological, and Social Environmental Factors of Loneliness and Satisfaction among Rural-to-Urban Migrants in Shanghai, China. International Journal of Comparative Sociology, 50, 155-182. http://dx.doi.org/10.1177/0020715208101597

Wong, D. F. K., Chang, Y. L., \& He, X. S. (2007). Rural Migrant Workers in Urban China: Living a Marginalized Life. International Journal of Social Welfare, 16, 32-40. http://dx.doi.org/10.1111/j.1468-2397.2007.00475.x

Wu, F. (2009). Land Development, Inequality and Urban Villages in China. International Journal of Urban and Regional Research, 33, 885-889. http://dx.doi.org/10.1111/j.1468-2427.2009.00935.x

Wu, W. (2002). Migrant Housing in Urban China Choices and Constraints. Urban Affairs Review, 38, 90-119. http://dx.doi.org/10.1177/107808702401097817

Wu, W. (2006). Migrant Intra-Urban Residential Mobility in Urban China. Housing Studies, 21, 745-765. http://dx.doi.org/10.1080/02673030600807506

Wu, W., \& Wang, G. (2014). Together but Unequal: Citizenship Rights for Migrants and Locals in Urban China. Urban Affairs Review, 50, 781-805. http://dx.doi.org/10.1177/1078087413518172

Wyly, E. K. (1996). Race, Gender, and Spatial Segmentation in the Twin Cities. Professional Geographer, 48, 431-444. http://dx.doi.org/10.1111/j.0033-0124.1996.00431.x

Zax, J. S., \& Kain, J. F. (1991). Commutes, Quits and Moves. Journal of Urban Economics, 29, 153-165. http://dx.doi.org/10.1016/0094-1190(91)90010-5

Zenou, Y. (2009). Urban Search Models under High-Relocation Costs. Theory and Application to Spatial Mismatch. Labor Economics, 16, 534-546. http://dx.doi.org/10.1016/j.labeco.2009.02.002

Zhang, L., Huang, J., \& Rozelle, S. (2002). Employment, Emerging Labor Markets, and the Role of Education in Rural China. China Economic Review, 13, 313-328. http://dx.doi.org/10.1016/S1043-951X(02)00075-5

Zhang, L., Zhao, S. X. B., \& Tian, J. P. (2003). Self-Help in Housing and Chengzhongcun in China’s Urbanization. International Journal of Urban and Regional Research, 27, 912-937. http://dx.doi.org/10.1111/j.0309-1317.2003.00491.x

Zhao, P., \& Howden-Chapman, P. (2010). Social Inequalities in Mobility: The Impact of the Hukou System on Migrants' Job Accessibility and Commuting Costs in Beijing. International Development Planning Review, 32, 363-384.

http://dx.doi.org/10.3828/idpr.2010.13 